\title{
A Study on Usage and Translation Strategies of Puns in English Commercial Advertisement
}

\begin{abstract}
YU Jing
Ningbo Dahongying University, Ningbo, China

Pun, a concise way of expressing humor and wit, is especially favored by advertisers to enhance the charm of language. Puns have long been regarded as "untranslatable" due to linguistic and cultural differences between two different languages. However, the author of this paper considers the translatability of puns to some extent. Although human may be lost in translation, translators can make various compensations to achieve similar effects in order to achieve the best translation of text. Combined with the analysis of examples, this paper provides a discussion on the classification of puns in English advertising. The author provides various ways to form puns in advertisement and proposes some suggestion for English commercial advertisement translation.

Keywords: pun, English commercial advertisement, translation strategies
\end{abstract}

\section{Introduction}

In daily life, advertisements have become an important part. People can find advertisement in anyway. Advertising not only plays an important role in the development of companies and sales but also affects people's lives. In modern society, English commercial advertising increased national exchanges and competition, so the English commercial advertising translation is becoming more and more useful.

Punning is one of the most common rhetorical devices used in advertisement. It is interesting. Puns can make language simple and subtle, vivid, novel, and unique. Clever use of ingenious puns can enhance the art of advertising language and expression results, and achieve the fundamental purpose of promotion.

\section{The General Introduction of Pun in English Commercial Advertisement}

Pun is not only a game of word, but also a common rhetorical in advertisement. It usually gives a word or phrase two different meanings. People use homophonic pun, homographic pun, grammatical pun, and idiomatic pun in English commercial advertisement.

\section{Classification of Pun}

There are many kinds of puns existing in English advertisements. In this paper, four major types of them to be talked, namely homophonic puns, homographic pun, grammatical pun, and idiomatic pun.

\section{Homophonic Pun}

Homophonic means two or more words have the same or similar sound but have different meanings. This Pun can not only add interest and sense of humor, but also attract attention of consumers, easy to remember.

YU Jing, student, Humanities College, Ningbo Dahongying University, under the guidance of advisor HE Ying. 
Example (1): "With so many carrots, I'll be a real gem!"

Muffin is one of products in Betty Croker from USA and it tastes like carrot. In this advertisement, "carrot" and "carat" have the same sound but have different meanings. The advertisement tells people that muffin is rich in nutrition and adequate in weight.

\section{Paronomasia}

Paronomasia is one of important means to create puns. Easily know from its name, paronomasia is a pun created by the homographic of a word. According to the etymology and grammatical, it can be divided into Polysemy Pun and Homonym Pun.

Example (2): "Money doesn't grow on trees. But it blossoms at our branches".

Lloyd Bank is in England. The branch has two different means in this advertisement. On the one hand, it simply means branch. On the other hand, it means the different parts of the bank. So, the advertisement wants to tell people if you put money on Lloyd Bank, your money will increase.

\section{Grammatical Pun}

If an advertisement has a problem in grammar, it will be called grammatical pun. Some especial verbs often have a flexible collocation. Whether fixed or free collocation is based on English word, then a word or a simple phrase has one or more characteristics.

Example (3): "Book at any station".

This advertisement is a book poster from a train station in UK. Book in this sentence can be considered to be a verb can also be a noun. When it is a verb, the meaning is book a ticket. When it is a noun, the meaning of advertisement is that people can read a lot of book in this place.

\section{Idiomatic Pun}

Each country has its own particular proverb. And they are usually some relatively fixed phrases match. But sometimes they can also be modified according to the needs of communication. This also provides a good source for advertisement.

Example (4): “A Mars a day keeps you work, rest and play”.

Mars Chocolate is a famous company in American. "An apple a day keeps the doctor away" is a popular idiom. This advertisement is similar to the idiom, thus the slogan is easy to be remembered.

\section{Functions of Pun in English Commercial Advertisement}

Pun is essentially a device for attracting and retaining the reader's attention. Therefore, pun is the most common use of rhetorical devices in English advertising. It increases the appeal, memory, and effectiveness of the advertising copy. The following are the main functions of puns in English advertising.

\section{Aesthetic Effect}

The first step to become a successful advertising is to attract the attention of consumers, because readers do not necessarily see ads, so ads must be attractive or striking to attract their attention from other topics or similar products. The aesthetic value of advertisement produces the pleasure of text, helps the realization of persuasion, and the ultimate aim of advertisement.

Example (5): "More sun and air for your son and heir".

This is an American beach advertisement. People can see the "son" has the same sound as "sun"; "air" has the same voice as "heir". It makes people feel surprised and can stimulate people's desire to go to the beach. 


\section{Humorous Effect}

Pun is a commonly used humor and satire writing, which make the speaker to express his intention indirectly through the homophone or convey a word meaning two. Therefore, puns can produce humorous effects and convey useful information about a product or service.

Example (6): Trust us. Over 5000 ears of experience.

This is an advertisement about hearing aids from American. From the textual point of view, people can know that many consumers have been using the product. But people can find homophonic puns in it when reading it. In this advertisement, "ears" means "years", it tells consumer this product has a long history and the good quality.

\section{Economical Effect}

Puns meet advertisers as an effective labor-saving and space saving device, so they are very economical. The use of puns can enrich a limited word, the implied meaning of puns, and the text content of surface meaning.

Example (7): Every Kid Should Have An Apple After School.

The Apple not only means a fruit but also a brand. Kids in American often eat snacks after school. "Apple" in this way means supplement children's physical strength and increase children's knowledge.

\section{Emotive Effect}

Imagine that if advertising leads a consumer to a good feeling, people will definitely be interested in the product or service in the advertisement. So people may take action. This function helps to achieve soft selling skills by attracting love, fame, humor, and patriotism.

Example (8): Blue Ribbon.

In American, the champion is often awarded blue ribbon, so blue ribbon usually means the first one or the best one. Company uses this brand to tell consumers the beer in their company has the best quality.

\section{The Application of Pun in Chinese Commercial Advertisement}

As a common promotion, Chinese and English advertisements use the same purpose, and the ultimate goal is to promote products or services. Despite the fact that English and Chinese belong to different language families, there are great differences in the characteristics of these two languages; they also share many similar language points. In various rhetorical devices, puns are also more attractive and persuasive in Chinese advertisements, which can be seen in the following example:

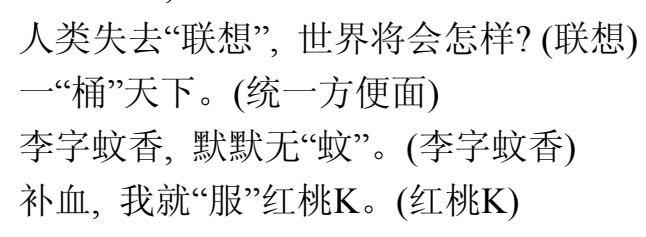

\section{Translation Strategies of Pun in English Commercial Advertisement}

If a word or a sentence used a homophonic pun in English, we can clearly know the mean of it. But when it is translated into Chinese, there will not be so interesting. In translating an English pun, people will inevitably meet some problem. But there is no word that is absolutely untranslatable. In the following article, the author will present some translation strategies. 


\section{Literal Translation and Free Translation}

Whether in English or Chinese, literal definition is not very accurate, can refer to the word-for-word translation and also includes the sentence-for-sentence translation. However, there are few people who agree with literal translation in the modern literary translators. The main reason, as Nida says, is that there is no language that is exactly the same, regardless of the meaning of symbols or the arrangement of linguistic signs. It can be said that there is no absolute consistency between languages. Therefore, there is no absolute and accurate translation. The translation produced by literal translation seems to have traces of translation, and it is not so smooth. Gradually, the boundaries between literal translation and free translation have begun to blur. Therefore, the translation of modern English advertising through the combination of literal translation and free translation makes the translation as far as possible to maintain the original sentence structure and rhetorical means while the language fluency.

Example (9A): What pleasure it gives to own the Bosom Friend in one's lifetime!

Translation: 人生得一《知音》足矣。

This is Bosom Friend (a magazine) advertising in China, here not only pointing out the wishes of people to have a lifetime friend, also alluding to the magazine is reader's companion, and readers can empathy.

Example (9B): Spoil yourself and not your figure.

Translation: 尽心地吃吧, 别担心体重。

On the one hand, "Spoil" means "Pet"; on the other hand, it also means "Destroy". Advertisers use puns to persuade ice cream lovers to eat follow their heart without worrying about their weight. It achieves good results. It is more suitable for the translation of the free translation, thus the author thinks better translation is 饱口福 而不发福。

\section{Foreignizing Translation and Domesticating Translation}

The foreignizing translation is intended to make the target language break through the target language, keep the foreign language in the original text, combine the foreign culture with the native culture, and retain the foreign language characteristics to the greatest extent. Domesticating translation aims at reducing the exotic, with a natural and fluent translation for the readers, the foreign language through easy to understand the language, reduces the acceptance and learning new things. From this point of view, the author tends to the foreignizing translation. In the continuous development of today, people must learn to accept new things, combination of advanced foreign culture and their own excellent culture to promote the development and promotion of culture.

Example (10): We take no pride in prejudice.

Translation: 我们不以偏见为荣。

It is an advertisement for The Times in England. Slogan is from Pride and Prejudice. Newspaper uses the title as advertising, to flaunt their fair and equity. In China to promote the Eight Honors and Eight Disgraces thus the author thinks better translation is 以公正为荣，视偏见为耻。

\section{Conclusion}

As a unique style, there are a variety of linguistic and rhetorical features in advertising. This article specifically discusses the different classifications of puns in English advertising which helps to stimulate the consumer's interest, hold their attention, and increase advertising art effect, make the advertisement more 
memorable and enhance the competitiveness of the products.

There is no absolute equivalence in translation and barriers will exist in the translation of puns. The translation strategies presented in this paper are only a small part of the English advertising translation. The author hopes the paper can provide some helps to Chinese companies in English advertisement translation.

\section{References}

Guidere, M. (2000). Translating ads. Paris: Harmattna.

KONG, T. (2011). On the translation of pun in English advertising. Xinjiang: Journal of Hotan Teachers College. Newmark, P. (2001). A textbook of translation. Shanghai: Shanghai Foreign Language Education Press.

Nida, E. A. (2001). Language, culture, and language translation. Shanghai: Foreign Language Education Press.

Nida, E. A., \& Charles, R. (2004). The theory and practice of translation. Shanghai: Shanghai Foreign Language Education Press.

YE, G. H. (2004). Pun and its translation in advertising English. Jiangsu: Journal of Nantong Institute of Technology (Social Science, 3 . 